\title{
Estabelecimento in vitro de Ocotea odorifera, O. catharinensis e O. porosa
}

\author{
Aline Moritz ${ }^{(1,2)}$, Juliana Degenhardt ${ }^{(3)}$, Leonardo Ferreira Dutra ${ }^{(4)}$, Fabrício Augusto Hansel ${ }^{(3)}$, Bruno Henrique de \\ Lima $^{(2)}$, Cristina do Rosário Batista Franceschi(2) e Luziane Franciscon ${ }^{(3)}$

\begin{abstract}
(1)Bolsista PIBIC/CNPq, E-mail: alinemoritz6@hotmail.com; (2)Pontifícia Universidade Católica do Paraná - PUC-PR, Rua Imaculada Conceição, 1155, CEP 80215-901, Prado Velho, Curitiba-PR. E-mails: cristinajf5@yahoo.com.br; ${ }^{(3)}$ Embrapa Florestas, Estrada da Ribeira, Km 111, C. P. 319, CEP 83411-000, Colombo-PR. E-mails: juliana@cnpf.embrapa.br; hansel@cnpf.embrapa.br; luziane@cnpf.embrapa.br; ${ }^{(4)}$ Embrapa Clima Temperado, BR 392, Km 78, CEP 94400-970, Pelotas-RS, E-mail: leo@cpact.embrapa.br
\end{abstract}

\begin{abstract}
Resumo - Várias espécies da família Lauraceae encontram-se em risco de extinção, devido ao alto valor comercial de suas madeiras e a consequente exploração das reservas naturais. Dentre elas, Ocotea porosa (imbuia), $O$. odorifera (canela-sassafras) e O. catharinensis (canela-preta) são de grande importância no Sul do Brasil, de onde são originárias. Estas espécies apresentam sementes recalcitrantes, o que dificulta sua regeneração natural. Além disso, a propagação por meio de estaquia e enxertia apresenta limitações. Este trabalho teve por objetivo avaliar a germinação e multiplicação in vitro das canelas preta e sassafrás na presença de BAP e carvão ativado e a germinação e multiplicação in vitro de imbuia sob diferentes concentrações de sacarose no meio de cultura. Para as canelas preta e sassafrás foram avaliadas duas concentrações de $\mathrm{NaClO}$ na desinfestação de embriões $(0,1 \%$ e $0,5 \%)$. Na fase de multiplicação, foi avaliado o efeito de BAP e carvão ativado. Para a imbuia, foi avaliada a influência da concentração de sacarose $(30,60,90$ ou 120 g.L.-1) na introdução e multiplicação in vitro. A porcentagem de germinação foi superior a $85 \%$ para as três espécies. Para a canela sassafrás, as melhores taxas de multiplicação foram obtidas na presença de $5 \mu \mathrm{mol} \cdot \mathrm{L}^{-1}$ de BAP. Para a imbuia, a concentração de 60 g.L. $\mathrm{L}^{-1}$ de sacarose no meio proporcionou as maiores taxas de multiplicação. Apesar de o estabelecimento da canela preta ter sido satisfatório, após algumas semanas no meio de multiplicação os explantes não apresentavam aparência normal e oxidaram.
\end{abstract}

Termos para indexação: BAP, carvão ativado, sacarose, conservação.

\section{In vitro Establishment of Ocotea odorifera, O. catharinensis and O. porosa}

\begin{abstract}
Several species of the Lauraceae family are endangered, due to the high value of their woods, and the consequent exploitation of natural populations. Among them, Ocotea porosa, O. odorifera and $O$. catharinensis, native from South Brazil, have recalcitrant seeds, what makes even more dificult their natural regeneration. This work aimed to evaluate in vitro seed germination and multiplication of $O$. odorifer $a$ and $O$. catharinensis in culture medium supplemented with activated charcoal and/or BAP and in vitro seed germination and multiplication of $O$. poros $a$ in culture medium supplemented with several concentrations of sucrose. The effect of BAP and activated charcoal were tested in the multiplication of $O$. catharinensis and $O$. odorifera and the effect of sucrose concentration $(30,60,90$ ou 120 g.L-1 $)$ was tested in the multiplication of $O$. porosa. The germination percentage was higher than $85 \%$ for all species. BAP promoted the highest multiplication rates for O. odorifera. O. porosa showed the best results for in vitro germination and multiplication on $60 \mathrm{~g} . \mathrm{L}^{-1}$ sucrose. The establishment of $O$. catharinensis was achieved, but after some weeks, in all media tested, the explants showed abnormalities, and finally died.
\end{abstract}

Index terms: BAP, activated charcoal, sucrose, conservation.

\section{Introdução}

O bioma Mata Atlântica, que abriga uma vasta diversidade biológica e um alto grau de endemismo, é considerado o bioma mais ameaçado do Brasil, por estar situado na região onde vive $70 \%$ da população brasileira, e onde se concentra a maior atividade industrial do País.
Estima-se que, atualmente, restem menos de $7 \%$ desse bioma (RIBEIRO et al., 2005). Apesar de sua ampla distribuição ao longo da costa brasileira, desde o Rio Grande do Norte até o Rio Grande do Sul, muitas das espécies endêmicas que compõem a Mata Atlântica estão em perigo de extinção. Entre elas as canelas sassafrás e preta e a imbuia, da família Lauraceae, que na região 
sul tem grande destaque econômico do ponto de vista madeireiro (CETNARSKI FILHO, 2003).

A canela sassafrás (Ocotea odorifera) é uma espécie de médio porte (15 a 20 metros) com ampla distribuição, desde o Rio Grande do Sul até a Bahia (CARVALHO, 2003). Sua frutificação acontece irregularmente entre os anos e raramente é abundante, sendo que o processo reprodutivo das plantas inicia-se somente aos 20 anos de idade. A semente é atacada por insetos e fungos antes e após a maturação fisiológica. Seu alto teor em óleo provoca a oxidação e rápida deterioração da semente, determinando uma baixa taxa de germinação (CARVALHO 1994). A canela-sassafrás durante muito tempo foi extremamente explorada por conter safrol em seu óleo essencial, o qual após a extração é convertido em outras valiosas substâncias, com largo emprego na perfumaria, medicina, como combustível em naves espaciais e outros setores industriais (CARVALHO, 1994).

A imbuia (O. porosa) é outra espécie de destaque na Mata Atlântica, e segundo Rizzini (1978) trata-se de uma árvore que comumente chega de 15 a 20 metros. A imbuia é uma árvore nativa do Brasil, e ocorre naturalmente nos estados de Goiás, Minas Gerais, Paraná, Rio de Janeiro, Santa Catarina e São Paulo. A floração acontece entre os meses de outubro e dezembro e a frutificação por sua vez ocorre nos meses de fevereiro a abril (CARVALHO, 2003). A Imbuia foi uma das árvores mais abundantes do Sul do Brasil, mas devido a sua valiosa madeira está ameaçada de extinção (NETO et al., 2002) e constitui a segunda espécie nativa em volume de madeira explorada, e esta exploração se deve a qualidade da madeira, a qual não é dura nem pesada, mas extremamente durável (RIZZINI, 1978).

A canela preta (O. catharinensis) trata-se de uma espécie florestal que atinge 25 a 30 metros de altura (RIZZINI, 1978). Sua distribuição ocorre naturalmente no Brasil nos estados de Minas Gerais, Paraná, Rio de Janeiro, Rio Grande do Sul, Santa Catarina e São Paulo. Sua floração ocorre entre os meses de junho e janeiro no Paraná, com os frutos maduros entre maio e agosto. Possui madeira muito visada por ser de fácil manuseio e por tomar bom polimento, tornando-se atraente quando envernizada. Entretanto, o principal interesse na planta é o óleo essencial presente no caule, o linalol, produto muito apreciado por seu aroma de rosa, e amplamente empregado na fabricação de cosméticos (CARVALHO, 2003).
A regeneração natural destas espécies é dificultada pela recalcitrância de suas sementes, as quais perdem a viabilidade em um curto período de tempo nos sistemas convencionais de conservação (e.g. câmara fria) (CARVALHO, 2003). A propagação vegetativa convencional por estaquia destas espécies apresenta baixa capacidade de enraizamento, como demonstrado por Högberg et al. (1998) na propagação de canela sassafrás.

As técnicas de propagação in vitro adequam-se a programas de introdução, multiplicação, conservação e intercâmbio de germoplasma, contribuindo para a preservação da variabilidade genética da espécie. Dentre as técnicas de conservação de material in vitro, a preservação sob condições de crescimento lento em laboratório é considerada eficiente (GRATTAPAGLIA; MACHADO, 1998). A germinação in vitro de embriões zigóticos imaturos e maturos pode ser utilizada para o resgate de embriões em programas de conservação e melhoramento genético, na recuperação de híbridos de cruzamentos incompatíveis e também como fonte de explante para a cultura de tecidos (ZHANG; LESPINASSE, 1991).

Estudos envolvendo o estabelecimento e multiplicação in vitro de espécies da família Lauraceae não são muito frequentes na literatura. Estudos relacionados a aspectos morfológicos, fisiológicos e bioquímicos já foram realizados para embriões zigóticos e somáticos (SANTA CATARINA et al., 2003) de espécies do Gênero Ocotea (SANTA CATARINA et al., 2006). Para outras espécies da família Lauraceae, como Laurus nobilis (CANHOTO et al. 1999), Persea americana Mill. (WITJAKSONO et al. 1999), O. catharinensis (VIANA; MANTELL 1999) e O. odorifera (SANTA CATARINA et al., 2001), a embriogênese somática foi induzida. Porém, a indução de culturas embriogênicas depende do genótipo, tipo de explante, estádio de desenvolvimento do explante e da composição do meio de cultivo in vitro (LITZ et al., 1998). Kowalski e Van Staden (2001) avaliaram o efeito de vários pré tratamentos no estabelecimento in vitro de $O$. bullata, espécie nativa da África do Sul (KOWALSKI; VAN STADEN, 2001).

O presente trabalho teve por objetivo estabelecer e multiplicar em condições in vitro canela sassafrás $(O$. odorifera), imbuia (O. porosa) e canela preta $(O$. catharinensis) visando tanto a conservação in vitro como o desenvolvimento de protocolo de micropropagação das espécies. 


\section{Material e Métodos}

\section{Material Vegetal}

Os experimentos foram realizados no Laboratório de Cultura de Tecidos Vegetais da Embrapa Florestas, Colombo, PR. As matrizes utilizadas localizam-se na fazenda Gralha Azul da PUCPR em Fazenda Rio Grande, PR (canela-sassafrás) e em Colombo, PR (canela-sassafrás, canela-preta e imbuia). As sementes foram coletadas durante os meses de outubro de 2008 para canela-preta e sassafrás e nos meses de janeiro e fevereiro de 2009 para a Imbuia, com o auxílio de um podão.

Os frutos coletados no estágio fisiológico maduro foram acondicionados em frascos de vidro de $1 \mathrm{~L}$, lacrados com plástico filme PVC. No laboratório, incialmente, os frutos foram despolpados manualmente e desinfestados em capela de fluxo laminar, com álcool $70 \%$ por 1 min seguido de hipoclorito de sódio $5 \%$ por $10 \mathrm{~min}$ e tríplice lavagem em água bidestilada e autoclavada.

Efeito de diferentes concentrações de $\mathrm{NaClO}$ na desinfestação e germinação in vitro de sementes das canelas preta e sassafrás

Os embriões de canela preta e canela sassafrás foram retirados com auxílio de pinças, e foram submetidos a dois tratamentos de desinfestação em capela de fluxo laminar: (i) hipoclorito de sódio a $0,5 \%$ por $10 \mathrm{~min}$ ou (ii) $0,1 \%$ por $10 \mathrm{~min}$, seguidos de tríplice lavagem em água destilada e autoclavada. Os embriões foram então inoculados em frascos de $7,5 \mathrm{~cm}$ de altura por $2,5 \mathrm{~cm}$ de diâmetro contendo $20 \mathrm{~mL}$ de meio de cultura $1 / 2 \mathrm{MS}$ (MURASHIGE; SKOOG, 1962) acrescido de 15 g.L.-1 de sacarose e 7 g.L $\mathrm{L}^{-1}$ de ágar. $\mathrm{O} \mathrm{pH}$ do meio foi ajustado para 5,8 antes da autoclavagem.

\section{Efeito da sacarose na germinação in vitro de embriões de imbuia}

Os embriões de imbuia após retirados foram desinfestados com hipoclorito de sódio a $0,5 \%$ por 10 min, seguido de tríplice lavagem em água destilada e autoclavada e em seguida foram inoculados em frascos de 7,5 cm de altura por $2,5 \mathrm{~cm}$ de diâmetro contendo meio MS acrescido de 1 g.L $\mathrm{L}^{-1}$ de carvão ativado, $7 \mathrm{~g}$. $\mathrm{L}^{-1}$ de ágar e diferentes concentrações de sacarose em dois experimentos. No primeiro, foram testadas as concentrações 30,60 e 90 g.L $L^{-1}$ de sacarose e no segundo 60,90 e 120 g.L $\mathrm{L}^{-1} . \mathrm{O} \mathrm{pH}$ dos meios foi ajustado para
5,8 antes da autoclavagem. Todos os embriões foram deixados no escuro por 7 dias em sala de crescimento com temperatura de $23 \pm 2{ }^{\circ} \mathrm{C}$, antes de serem colocados sob intensidade luminosa de $84 \pm 4 \mu \mathrm{mol} \mathrm{m}^{-2}$. $\mathrm{s}^{-1} \mathrm{sob}$ fotoperíodo de 16 horas de luz e 8 horas de escuro.

Efeito do BAP e do carvão ativado na multiplicação in vitro das canelas preta e sassafrás

Após a germinação dos embriões, quando apresentavam aproximadamente $2 \mathrm{~cm}$ de comprimento, os explantes de canela sassafrás e canela preta foram submetidos aos seguintes tratamentos, em frascos de $7,5 \mathrm{~cm}$ de altura por $2,5 \mathrm{~cm}$ de diâmetro:

T1) Meio MS acrescido de 1,5 g.L. $\mathrm{L}^{-1}$ de carvão ativo e 7 g.L $L^{-1}$ de ágar.

T2) Meio MS acrescido de 1,5 g.L. $\mathrm{L}^{-1}$ de carvão ativo, $5 \mu$ mol.L ${ }^{-1}$ de 6-benzilaminopurina (BAP) e 7 g. L $^{-1}$ de ágar.

T3) Meio MS acrescido de $5 \mu \mathrm{mol} \mathrm{L}^{-1}$ de BAP e $7 \mathrm{~g}$. $\mathrm{L}^{-1}$ de ágar.

Efeito da sacarose na multiplicação in vitro de imbuia

Para os explantes de imbuia foram mantidos os mesmos meios da fase de estabelecimento, de acordo com cada experimento, ou seja, meio MS acrescido de 30,60 ou 90 g.L $\mathrm{L}^{-1}$ ou 60,90 ou 120 g.L. ${ }^{-1}$ de sacarose (para o primeiro e segundo experimentos, respectivamente), acrescidos de 1 g.L. ${ }^{-1}$ de carvão ativo e 7 g.L. L $^{-1}$ gar, com o $\mathrm{pH}$ ajustado para 5.8 .

\section{Avaliação e condição da sala de crescimento}

Para os experimentos de estabelecimento foram avaliados 60 dias após a introdução o número de embriões germinados sadios, com fungos, bactérias e oxidados.

Para os experimentos de multiplicação, após 30 dias as seguintes variáveis foram avaliadas: presença de raiz, comprimento de raiz, comprimento da parte aérea, número de folhas, presença de calo e número de brotações. O segundo experimento da imbuia foi avaliado excepcionalmente aos 60 dias. Cada experimento constou de 20 plântulas por tratamento, divididas em 5 repetições com quatro indivíduos em cada uma, em delineamento inteiramente casualizado. As análises estatísticas foram realizadas no software estatístico R (2009). Inicialmente foi realizada a análise de variância (ANOVA) para todas as variáveis, sendo o qui-quadrado usado para as variáveis discretas e o teste F para as variáveis contínuas. Quando ocorreu diferença significativa entre as médias, estas foram comparadas 
entre si por contraste ortogonal e Tukey a $\mathrm{p}<0,05$ para as variáveis discretas e contínuas, respectivamente. Para a imbuia, as variáveis foram transformadas em raiz quadrada, exceto para número de folhas onde foi usado $\log (\mathrm{x}+1)$.

Todos os materiais vegetais foram acondicionados em sala de crescimento com temperatura de $23 \pm 2{ }^{\circ} \mathrm{C}$ e intensidade luminosidade de $84 \pm 4 \mu \mathrm{mol} \mathrm{m}^{-2} \cdot \mathrm{s}^{-1} \mathrm{sob}$ fotoperíodo de 16/8 horas.

\section{Resultados e discussão}

\section{Efeito de diferentes concentrações de $\mathrm{NaClO}$ na desinfestação e germinação in vitro de embriões das canelas preta e sassafrás}

Na desinfestação dos embriões da canela preta e canela sassafrás ambas as assepsias testadas foram eficientes, apresentando uma grande porcentagem de plantas germinadas sadias (Figuras 1A e 1B). Os resultados obtidos para canela sassafrás pela assepsia usada foram muito próximos, com médias de $81 \%$ ( $\mathrm{NaClO} 0,1$ $\%)$ e $85 \%(\mathrm{NaClO} 0,5 \%)$ de embriões germinados sadios (Figura 1A). O mesmo foi evidenciado por Santa Catarina et al. (2001), no qual a desinfestação em frutos de $O$. odorifera (canela-sassafrás) alcançou a porcentagem média de germinação de $80 \%$. Nesses testes as médias de oxidação e de contaminação por fungos respectivamente foram de $4 \%$ e $15 \%$ ( $\mathrm{NaClO}$ $0,1 \%)$ e de $6 \%$ e $9 \%$ ( $\mathrm{NaClO}$ 0,5\%). Não foi observada contaminação por bactérias (Figura 1A).

Para a canela preta, as médias de embriões germinados foram de $86 \%$ ( $\mathrm{NaClO} 0,1 \%)$ e de $85 \%$ ( $\mathrm{NaClO} 0,5 \%$ ) (Figura 1B). Não foi observada a presença de embriões oxidados ou contaminados por bactérias nos tratamentos, e a porcentagem de embriões contaminados por fungos foi em média de $14 \%$ para $\mathrm{NaClO} 0,1 \%$ e $15 \%$ para $\mathrm{NaClO} 0,5 \%$, sugerindo que não houve influência do hipoclorito de sódio nas concentrações testadas.

O hipoclorito de sódio é bastante utilizado para desinfestações de explantes no cultivo in vitro e a concentração varia bastante de acordo com a espécie. Em O. porosa, Vicentini (1995) obteve 73,3 \% de brotações sem contaminação utilizando $0,5 \%$ de $\mathrm{NaClO}$ por 10 min, enquanto para desinfestação de $O$. odorifera, o tratamento de desinfestação foi mais eficaz com 0,75 $\%$ de solução de $\mathrm{NaClO}$ por 10 minutos. Segundo os resultados obtidos, a concentração de $\mathrm{NaClO}$ de $0.5 \%$ pode ser recomendada na assepsia das canelas preta e sassafrás, uma vez que não houve contaminação por bactérias e o número de explantes oxidados foi semelhante e baixo, sugerindo que não houve efeito tóxico a esta concentração.

\section{Efeito da sacarose na germinação in vitro de sementes de imbuia}

As médias de embriões germinados e sadios no primeiro experimento foram de $90 \%$ nos meios de cultura acrescido com 30 g. $\mathrm{L}^{-1}$ de sacarose e $95 \%$ nos meios com 60 e 90 g.L. - $^{-1}$ (Figura 1C). Estes resultados foram superiores aos encontrados por Pelegrini (2008), que também utilizou estas concentrações de sacarose, obtendo os melhores resultados com 90 g.L. $\mathrm{L}^{-1}$ de sacarose, com uma taxa de germinação de 59,4\%.

O número de embriões oxidados nas três espécies foi baixo, provavelmente devido à presença de carvão ativado no meio de cultura, o qual auxilia na adsorção dos compostos fenólicos, aliado às baixas concentrações de hipoclorito de sódio e ao fato dos embriões terem permanecido por 7 dias no escuro. A contaminação por fungos também foi baixa, mesmo com assepsias com baixas concentrações de hipoclorito de sódio. Além da desinfestação, a proteção natural do embrião pela

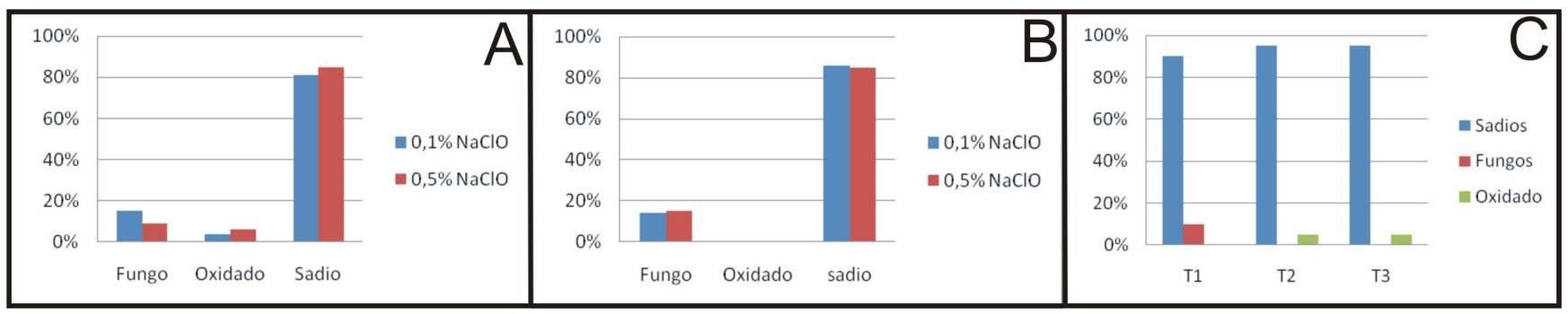

Figura 1. Médias de contaminação por fungos, embriões oxidados e germinados (sadios) na desinfestação de (A) - canelasassafrás, (B) - canela-preta $0,1 \%$ e $10,5 \%$ de $\mathrm{NaClO}$ e (C) - imbuia sob diferentes concentrações de sacarose no meio de germinação de embriões de imbuia - T1 - 30 g.L ${ }^{-1}$; T2 - 60 g.L e $^{-1}$ T3 - 90 g.L ${ }^{-1}$. 
estrutura da semente deve ter contribuído para estas baixas taxas.

\section{Efeito do BAP e do carvão ativado na multiplicação in vitro das canelas preta e sassafrás}

Em canela-sassafrás e preta foram testadas a presença e a ausência de BAP $\left(5 \mu \mathrm{mol} . \mathrm{L}^{-1}\right)$ e carvão ativado $\left(1,5 \mathrm{~g} . \mathrm{L}^{-1}\right)$ em meio de cultura MS. Para a canela sassafrás somente para a variável número de brotos houve diferença estatística $(p<0,05)$ entre os tratamentos, com $5 \mu \mathrm{mol} . \mathrm{L}^{-1}$ de BAP, apresentando resultados superiores aos demais, e média de 1,4 brotações formadas por explante (Tabela 1). Para as outras variáveis avaliadas não houve diferença estatística significativa, resultados que corroboram os obtidos por Santa Catarina et al. (2001), que testando as concentrações de 0 e $4,4 \mu$ mol.L-1 de BAP no meio de cultura não observaram diferenças na germinação e no pré desenvolvimento dos embriões de canela sassafrás. No entanto, a taxa de multiplicação obtida ainda é muito baixa, sugerindo que outros fitorreguladores e em diferentes concentrações devem ser testados para esta espécie.

Para a imbuia, Pellegrini (2008) observou que o meio de cultura MS, suplementado com $5 \mu \mathrm{M}$ de BAP foi mais eficiente para a multiplicação da imbuia, proporcionando 5,3 brotações por explante, após quatro subcultivos.
Tabela 1. Médias e erros padrões dos tratamentos para as variáveis número de brotações (NB), número de folhas (NF), presença de raiz (PR), comprimento da parte aérea (CAP) e comprimento de raiz (CR), avaliadas para a canela sassafrás. T1 meio MS normal com 1,5 g. $\mathrm{L}^{-1}$ de carvão ativo, T2 meio MS normal com 1,5 g.L. $\mathrm{L}^{-1}$ de carvão ativo e $5 \mu \mathrm{mol} . \mathrm{L}^{-1}$ de BAP e T3 meio MS normal, com $5 \mu$ mol.L ${ }^{-1}$ de BAP.

\begin{tabular}{|c|c|c|c|c|}
\hline & \multicolumn{4}{|c|}{ Significativas } \\
\hline & \multicolumn{4}{|l|}{ NB* } \\
\hline $\mathrm{T} 1$ & $0,12 \pm 0,09^{\mathrm{b}}$ & & & \\
\hline $\mathrm{T} 2$ & $0,12 \pm 0,07^{\mathrm{b}}$ & & & \\
\hline \multirow[t]{3}{*}{$\mathrm{T} 3$} & $0,72 \pm 0,34^{\mathrm{a}}$ & & & \\
\hline & \multicolumn{4}{|c|}{ Não significativas } \\
\hline & NF & PR & CAP (cm) & CR (cm) \\
\hline Médias & $4,97 \pm 0,78$ & $0,27 \pm 0,09$ & $0,82 \pm 0,14$ & $0,40 \pm 0,18$ \\
\hline
\end{tabular}

A emissão de novas brotações pode ser observada no tratamento com $5 \mu \mathrm{mol} . \mathrm{L}^{-1}$ de BAP (Fig 2C), enquanto nos demais tratamentos isso não foi observado (Fig $2 \mathrm{~A}$ e $2 \mathrm{~B}$ ), mesmo quando usado BAP na presença de carvão ativado, sugerindo que esse componente pode estar adsorvendo esta citocinina e neutralizando seu efeito na indução de novas brotações. Costa (2006) afirma em seu trabalho com bananeira cultivada in vitro na presença do carvão ativado que, independentemente das concentrações de BAP, não existe efeito positivo na indução de novas brotações, provavelmente devido ao fato do carvão ativado adsorver os reguladores de crescimento.

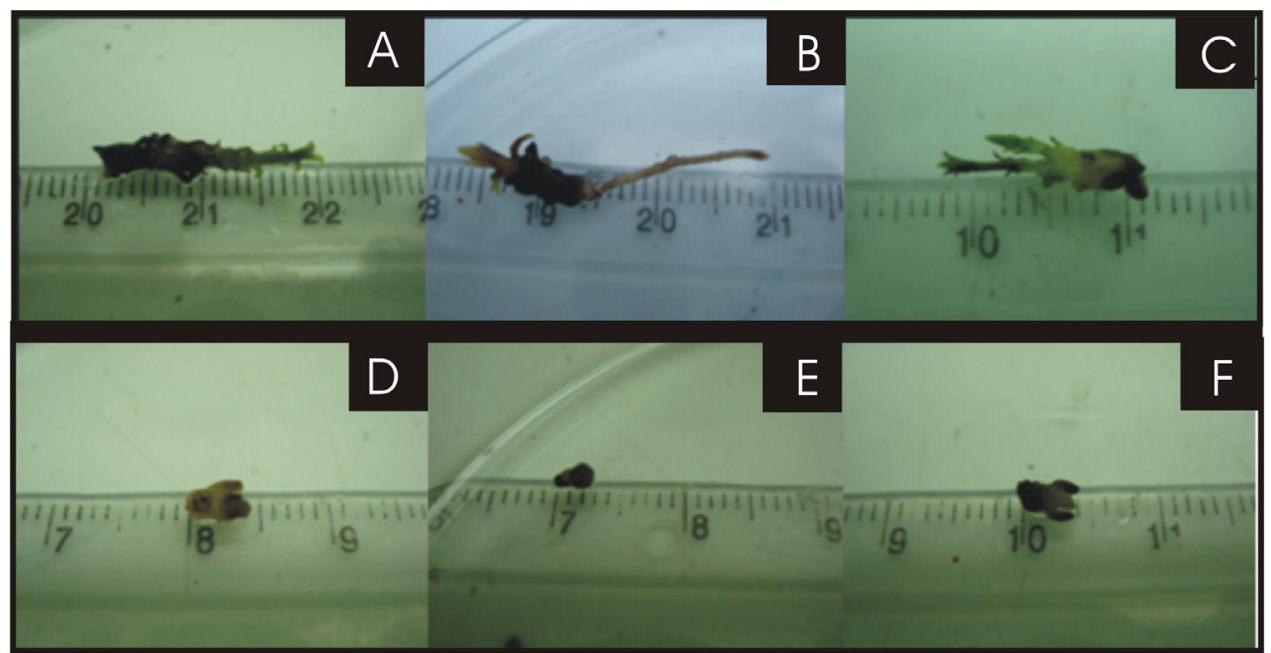

Figura 2. Aspectos visuais para os diferentes tratamentos para canela-sassafrás, T1 meio MS normal com 1,5 g. $\mathrm{L}^{-1}$ de carvão ativo (2A), T2 meio MS normal com 1,5 g.L. $\mathrm{L}^{-1}$ de carvão ativo e $5 \mu \mathrm{mol} \mathrm{L}^{-1}$ de BAP (B) e T3 meio MS normal, com $5 \mu$ mol. $\mathrm{L}^{-1}$ de BAP (C) e para canela preta, T1 meio MS normal, com $1,5 \mathrm{~g}$ de carvão ativo (D), T2 meio MS normal, com $1,5 \mathrm{~g}$ de carvão ativo e $5 \mu \mathrm{mol} . \mathrm{L}^{-1}$ de BAP (E) e T3 meio MS normal, com $5 \mu$ mol. $L^{-1}$ de BAP (F). 
A emissão de novas brotações é importante, pois dela depende a multiplicação in vitro da espécie. Para a canela-sassafrás os resultados de multiplicação in vitro obtidos por Vicentini (1995) não foram suficientes para a propagação massal de mudas. $O$. bullata, outra Lauraceae, demonstrou ser recalcitrante para a micropropagação, devido à presença de vários compostos fenólicos (KOWALSKI; VAN STADEN, 2001).

Para canela preta, os tratamentos não apresentaram diferença estatística, sugerindo que o BAP e o carvão ativado, ou a combinação destes, nas concentrações testadas, não promovem aumento das taxas de multiplicação dessa espécie (Tabela 2). Além disso, o desenvolvimento dessa espécie foi muito lento, semelhante ao observado para plantas germinadas ex vitro (CARVALHO, 2003), sugerindo uma maior recalcitrância dessa espécie ao cultivo in vitro em comparação com a canela sassafrás.

Embora o crescimento lento seja interessante para a conservação in vitro, os explantes de canela preta não apresentaram aspecto saudável, indicando que os testes realizados não foram satisfatórios para a conservação da canela preta. Isto é claramente observado nas Figuras $2 \mathrm{D}, 2 \mathrm{E}$ e $2 \mathrm{~F}$, onde são apresentados os explantes com tamanhos diminutos e com tecidos oxidados.

\section{Efeito da sacarose na multiplicação in vitro de imbuia}

Para imbuia, foram testadas diferentes concentrações de sacarose em dois experimentos. No primeiro, houve diferença estatística para as variáveis número de folhas e comprimento de parte aérea, sendo que o tratamento com 60 g. $\mathrm{L}^{-1}$ de sacarose apresentou as melhores médias (5,85 cm e $1,03 \mathrm{~cm}$, respectivamente) (Tabela 3$)$. Para as demais variáveis não houve diferença estatística. No tratamento com 60 g. $\mathrm{L}^{-1}$ de sacarose as plantas inicialmente apresentaram coloração rósea (Figura 3B), sugerindo o efeito de estresse sobre os explantes. No entanto, após alguns dias, a partir do centro das estruturas surgiram explantes com aparência normal (Figuras 3D e 3E). O tratamento com 30 g.L.- de sacarose pode ser também interessante, pois as plantas apresentaram desenvolvimento lento conforme mostrado para as variáveis número de folhas e comprimento de parte aérea, com aspecto sadio, sugerindo que esse tratamento poderia ser utilizado para a conservação in vitro da espécie (Figura 3A). No tratamento com 90 g.L. $\mathrm{L}^{-1}$ de sacarose as plantas não apresentaram um padrão de desenvolvimento sadio, provavelmente indicando um caráter fitotóxico dessa concentração de sacarose na manutenção in vitro da imbuia. O mesmo foi observado por Kozai (1991) e Caldas et al. (1998) nos quais a concentração de sacarose foi um fator determinante no crescimento, sendo que as concentrações elevadas provocaram crescimento reduzido e até a morte de mudas.

Tabela 2: Médias e erros padrões entre tratamentos para as variáveis, número de brotações (NB) número de folhas (NF), presença de raiz (PR), comprimento da parte aérea (CAP) e comprimento de raiz (CR) avaliadas para a canela preta.

\begin{tabular}{cccccc}
\hline & & \multicolumn{4}{c}{ Não significativas } \\
& NB & NF & PR & CAP & CR \\
\hline Médias & $0,05 \pm 0,03$ & $1,72 \pm 0,29$ & $0,12 \pm 0,05$ & $0,25 \pm 0,06$ & $0,05 \pm 0,03$ \\
\hline
\end{tabular}


Tabela 3. Médias e erros padrões entre tratamentos para as variáveis explantes vivos, oxidados, número de folhas (NF), comprimento da parte aérea (CAP), presença de calo (PC), presença de raiz (PR) e comprimento de raiz (CR) avaliadas para a imbuia. Meio $0,5 \mathrm{MS}$ com $1 \mathrm{~g} \cdot \mathrm{L}^{-1}$ de carvão ativo e 7 g.L. - $^{-1}$ de ágar acrescido 30,60 ou 90 g.L. - $^{-1}$ de sacarose, de acordo com cada tratamento.

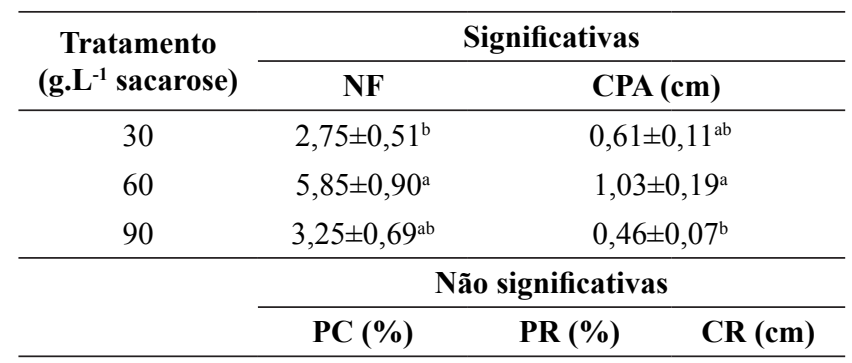

No segundo experimento, houve diferença estatística entre os tratamentos para todas as variáveis avaliadas. A concentração de 120 g. $\mathrm{L}^{-1}$ de sacarose influenciou negativamente as características avaliadas, sugerindo certo grau de toxicidade nessa concentração. De maneira geral, as concentrações de 60 e 90 apresentaram resultados semelhantes, com exceção das características avaliadas para a raiz, para as quais a concentração de 60 g.L.- ${ }^{-1}$ foi estatisticamente superior. Nas concentrações maiores do carboidrato, os explantes não apresentaram aparência saudável, corroborando os resultados dos primeiro experimento.

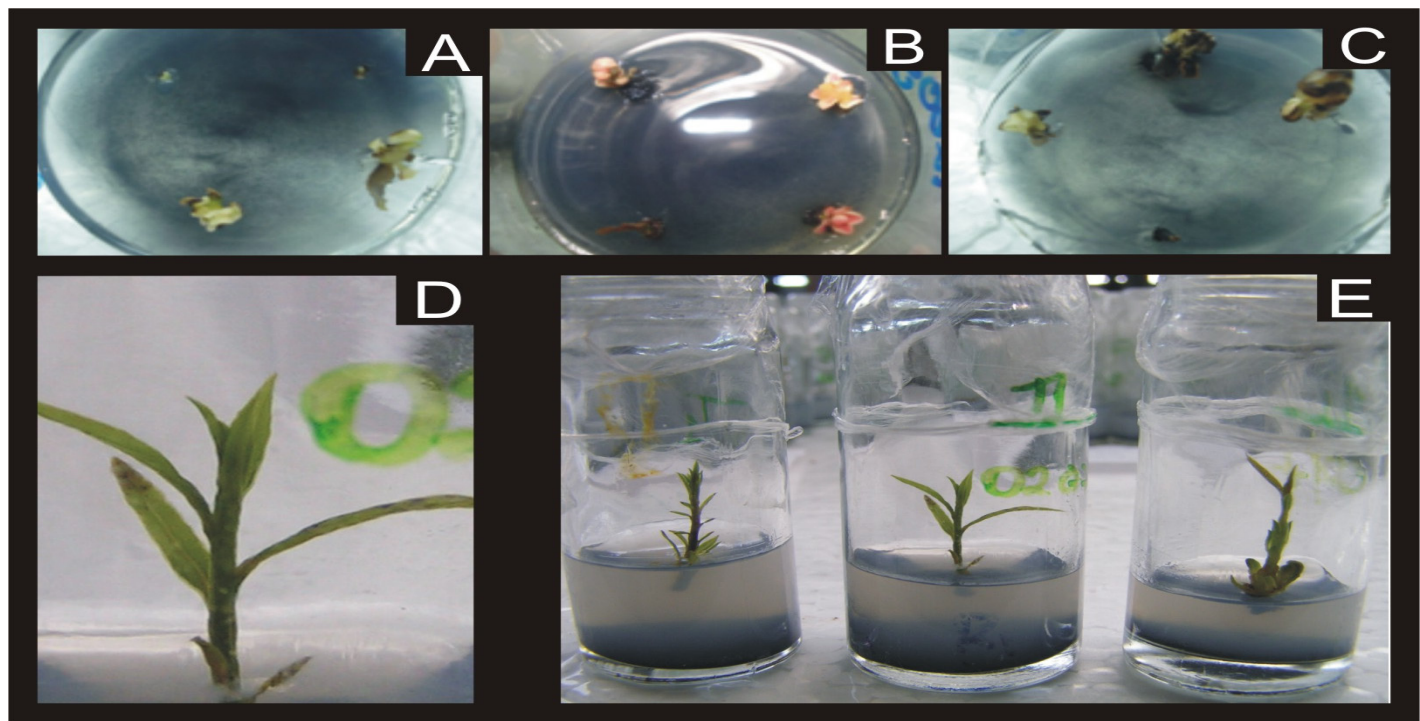

Figura 3. Aspectos visuais para os diferentes tratamentos com imbuia, T1 meio 0,5 MS com 1 g.: $\mathrm{L}^{-1}$ de carvão ativo e 30 g.L. $\mathrm{L}^{-1}$ de sacarose (A), T2 meio $1 / 2 \mathrm{MS}$ com 1 g.L. $\mathrm{L}^{-1}$ de carvão ativo e $60 \mathrm{~g} . \mathrm{L}^{-1}$ de sacarose (B) e T3 meio 0,5 MS com 1 g.L. $\mathrm{L}^{-1}$ de carvão ativo e 90 g. $\mathrm{L}^{-1}$ de sacarose (C) e plântulas de imbuia na fase de multiplicação (D e E).

Tabela 4. Médias e erros padrões entre tratamentos para as variáveis explantes vivos, oxidados, número de folhas (NF), comprimento da parte aérea (CAP), presença de raiz (PR) e comprimento de raiz (CR) avaliadas para a imbuia. Meio $0,5 \mathrm{MS}$ com $1 \mathrm{~g} \mathrm{~L}^{-1}$ de carvão ativo e $7 \mathrm{~g} . \mathrm{L}^{-1}$ de ágar acrescido 60,90 ou 120 g. $\mathrm{L}^{-1}$ de sacarose, de acordo com cada tratamento.

\begin{tabular}{ccccc}
\hline \multirow{2}{*}{$\begin{array}{c}\text { Tratamento } \\
\text { g.: } \mathbf{L}^{-1} \text { sacarose) }\end{array}$} & NF & CPA (cm) & PR & CR (cm) \\
\cline { 2 - 5 } & $4,40 \pm 0,940^{\mathrm{a}}$ & $1,236 \pm 0,396^{\mathrm{a}}$ & $0,360 \pm 0,075^{\mathrm{a}}$ & $0,420 \pm 0,157^{\mathrm{a}}$ \\
90 & $2,28 \pm 0,568^{\mathrm{ab}}$ & $0,524 \pm 0,183^{\mathrm{ab}}$ & $0,120 \pm 0,049^{\mathrm{b}}$ & $0,036 \pm 0,016^{\mathrm{b}}$ \\
120 & $1,28 \pm 0,224^{\mathrm{b}}$ & $0,216 \pm 0,068^{\mathrm{b}}$ & $0 \pm 0^{\mathrm{c}}$ & $0 \pm 0^{\mathrm{b}}$ \\
\hline
\end{tabular}

* Médias comparadas entre si por contraste Tukey $(\mathrm{p}<0,05)$. 
A micropropagação de imbuia via proliferação de gemas axilares foi relatada por Vicentini (1995). A taxa média de multiplicação obtida foi de 2,4 brotações por explante em meio de cultura MS acrescido de 3,23 $\mu \mathrm{M}$ de BAP.

\section{Conclusões}

- Os processos de desinfestação na canela preta e sassafrás com $0,1 \%$ e $0,5 \%$ de $\mathrm{NaClO}$ são eficientes, e possibilitam alta taxa de germinação de embriões.

- Para a canela-sassafrás a adição de $5 \mu \mathrm{mol} . \mathrm{L}^{-1}$ de BAP sem a presença de carvão ativado promove a melhor taxa de multiplicação dos explantes.

- Para a canela-preta, os testes de multiplicação realizados não foram satisfatórios, sendo necessários novos estudos para a conservação in vitro.

- Para a imbuia a concentração de 60 g.L.-1 de sacarose favorece a germinação e multiplicação in vitro dos explantes.

\section{Agradecimentos}

Os autores agradecem ao $\mathrm{CNPq}$ pela concessão da bolsa à primeira autora.

\section{Referências}

CALDAS, L.S.; BUSO, J.A. (Eds.). Cultura de tecidos e transformação genética de plantas. Brasília: Embrapa-SPI/ Embrapa-CNPH. P.183-260, 1998.

CARVALHO, P. E. R. Espécies arbóreas brasileiras. Colombo, PR.: EMBRAPA-FLORESTAS, v. 1, 2003, 1039 p.

CARVALHO, P. E. R. Espécies florestais Brasileiras: recomendações silviculturais, potencialidades e uso da madeira. Colombo: Embrapa. 1994. 640 p.

CETNARSKI, FILHO, R. Regeneração natural de Ocoea odorifera (Vell) Rohwer (canela-sassafrás) em Floresta Ombrófila Mista, no Estado do Paraná. 2003. 79 f. Dissertação (Mestrado em Engenharia Florestal) - Universidade Federal do Paraná, Curitiba.

COSTA, F. H. S.; PEREIRA. J. E. S.; PEREIRA, M. A. A.; OLIVEIRA, J. P. Efeito da interação entre carvão ativado e N- 6 benzilaminopurina na propagação in vitro de bananeira, $\mathrm{CV}$. GRAND NAINE (AAA)1. Revista Brasileira de Fruticultura, Jaboticabal - SP, v. 28, n. 2, p. 280-283, 2006.

GRATTAPAGLIA, D.; MACHADO, M.A. Micropropagação. In: TORRES, A.C.; CALDAS, L.S.; BUSO, J.A. (Eds.). Cultura de tecidos e transformação genética de plantas. Brasília: EmbrapaSPI/Embrapa-CNPH. P.183-260, 1998.
KOZAI, T. Micropropagation under photoautotrophic conditions. In RODRIGUES, I. C. S.; RIBEIRO, M. V.; BRAGA, E. J. B. Multiplicação in vitro de Alternanthera dentata Moench em meio MS suplementado com diferentes concentrações de sacarose e BAP. In: Congresso de Iniciação Científica, XVI. 2007, Pelotas, RS.

KOWALSKI, B.; VAN STADEN, J. In vitro culture of two threatened South African medicinal trees - Ocotea bullata and Warburgia salutaris. Plant Growth Regulation. Vol. 34, p. 223228, 2001.

MARCHIORI, J. N. C. Dendrologia das Angiospermas. Das Magnoliáceas às Flacurtiáceas. Santa Maria: UFSM, 1997. 62-64, p.

NETO, R. M. R.; WATZLAWICK, L. F.; CALDEIRA, M. V. W.; SCHOENENGER, E.R. Análise florística e estrutural de um fragmento de Floresta Ombrófila Mista

Montana, situado em Críuva, RS - Brasil. Ciência Florestal, Santa Maria, v. 12,n. 1, p. 29-37, 2002.

PASQUAL, M. Textos acadêmicos: meios de cultura. Lavras: FAEPE/UFLA, 2001. 127p.

PELEGRINI, L. L.; MICROPROPAGAÇÃO DE Ocotea porosa (NESS EX MARTIUS) LIBERATO BARROSO (IMBUIA) 2008. 91 f. Dissertação (Mestrado em Botânica) - Universidade Federal do Paraná, Curitiba.

RIBEIRO, C. A. A. S.; SOARES, V. P.; OLIVEIRA, A. M. S.; GLERIANI, J. M. O desafio da delimitação de áreas de preservação permanente. Revista Árvore, Viçosa, v. 9, n. 2, p. 203-212, 2005.

RIZZINI, C. T. Árvores e Madeiras Úteis do Brasil. Manual de Dendrologia Brasileira. São Paulo: Edgard Blucher, 1978. 80-82, p.

SANTA CATARINA, C.; MACIEL, S.C.; PEDROTTI, E.L. Germinacao in vitro e embriogenese somatica a partir de embrioes imaturos de canela sassafras (Ocotea odorifera Mez). Revista Brasileira de Botanica, n. 24 (suplemento), p. 501-510, 2001.

SANTA CATARINA, C., RANDI, A.M.; VIANA, A.M. Growth and accumulation of storage reserves by somatic embryos of Ocotea catharinensis Mez. (Lauraceae). Plant Cell, Tissue and Organ Culture n. 74, p.67-71, 2003.

SANTA CATARINA, C.; SILVEIRA, V.; BALBUENA, T.; VIANA, A.M.; ESTELITA, E.M.; HANDRO, W.; FLOH, E.I. IAA, ABA, polyamines and free amino acids associated with zygotic embryo development of Ocotea catharinensis. Plant Growth Regulation n. 49. P. 237-247, 2006.

VICENTINI, L.S. Propagação vegetativa "in vitro"de imbuia (Ocotea porosa Nees)e sassafrás (Ocotea odorífera Vellozo).1995. 68f. Dissertação (Mestrado em Engenharia Florestal)- Universidade Federal do Paraná, Curitiba.

Recebido em 07 de agosto de 2009 e aprovado em 18 de dezembro de 2009 